\title{
Research on Recognition and Evaluation of Traffic Guide Sign
}

\author{
Li Yuan, ${ }^{1}$ Ming-jie Cai, ${ }^{1}$ Tang-yi Guo, ${ }^{2}$ and Yu Jiang ${ }^{3}$ \\ ${ }^{1}$ College of Civil and Transportation Engineering, Hohai University, Nanjing 210098, China \\ ${ }^{2}$ School of Automation, Nanjing University of Science and Technology, Nanjing 210094, China \\ ${ }^{3}$ College of Civil Aviation, Nanjing University of Aeronautics and Astronautics, Nanjing 210016, China
}

Correspondence should be addressed to Li Yuan; yuanlibox@sina.com

Received 20 January 2015; Accepted 7 April 2015

Academic Editor: Wei (David) Fan

Copyright (C) $2015 \mathrm{Li}$ Yuan et al. This is an open access article distributed under the Creative Commons Attribution License, which permits unrestricted use, distribution, and reproduction in any medium, provided the original work is properly cited.

\begin{abstract}
Traffic guide signs are effective only when they are clearly recognized by drivers. Three experiments were conducted in this study. In the first, the influence factors of guide sign recognition were studied. This study investigated 11 main factors with a convenience sample of drivers from Nanjing city in China. Weights of different influence factors were obtained through analytic hierarchy process (AHP). The results showed that the setting position, occlusion degree, and character size of guide sign had the most significant influence on the guide sign recognition, while other factors were less important. In the second stage, an evaluation model of guide sign recognition was developed based on weights of different factors. Four equations were presented to calculate the comprehensive score of guide sign, and the level of recognition was divided into five grades according to the comprehensive score. At last, a typical case in Nanjing was studied to verify the rationality and reliability of the evaluation model. Results from the real application indicate that the method had good applicability and can be used by traffic engineers.
\end{abstract}

\section{Introduction}

Traffic signs provide important information for regulating, guiding, or warning the behaviors of drivers in order to make driving safer and easier [1]. However, with the continuous development of city scale and road network, the service of traffic signs has lagged far behind. The guide sign is a type of traffic sign that help drivers reach their destinations conveniently, quickly, and comfortably and thus improve the efficiency of transportation system [2]. US Department of Transportation [3] claimed that an improvement project for traffic signs would lead to a $34 \%$ reduction in fatal accidents. However, if the guide signs cannot be clearly recognized by drivers, they serve little purpose. Therefore, there is need for detailed research of guide sign recognition. Then what factors can influence the recognition? What about the importance of different influence factors? How to evaluate the guide sign recognition? These questions are investigated in this study.

Guide sign has been a hot topic of considerable interest to researchers. Ng and Chan [4] studied the influence of a symbol's visual features (color, shape, and size) and cognitive features (familiarity, concreteness, complexity, meaningfulness, and semantic distance). Gao et al. [5] found that color and shape features extracted using vision models can perform accurate recognition for traffic signs located at a reasonable distance for still images under various viewing conditions. Al-Madani and Al-Janahi [6] investigated the relationship between drivers' personal characteristics and their comprehension of posted signs; they found that drivers' years of education, gender, monthly income, and nationality have significant effect on their understanding of traffic signs. There are some limitations of these studies: the research objects were mainly concerned with some basic features (especially color and shape) and personal characteristics of drivers; many other influence factors should be taken into account. Prieto and Allen [7] proposed a new method for the detection and recognition of traffic signs using self-organizing maps (SOM). Liu and $\mathrm{Lu}[8]$ studied the technology of guide sign setting based on front distance model which was presented to improve guide sign recognition. Zaklouta and Stanciulescu [9] presented a three-stage real-time recognition system of traffic signs, consisting of segmentation, detection, and classification phase. Souani et al. [10] proposed to implement the application of automatic recognition of road signs in real 
time by optimizing the techniques used in different phases of the recognition process. In this study, 11 main influence factors were selected to survey. The results are effective on guide sign of common road only; namely, other roads are not within the scope of this study.

As is readily apparent in the above brief review, a wide range of methods and measures have been used to study guide sign recognition. However, the importance of different influence factors remains unknown, and little research has been done in the evaluation of guide sign recognition. The aim of this study is to discuss the importance of different factors and the evaluation method of guide sign recognition. The paper proceeds as follows: (1) to determine weights of 11 factors and (2) to establish an evaluation model of guide sign recognition.

\section{Method}

The method adopted here involved questionnaires to be completed by the drivers who were selected randomly based on stratified random sampling technique. The stratification was based on gender, age, occupation, and years of driving license.

This research included three experiments. In the first, the influence factors of guide sign recognition were studied. In the second, the evaluation model of guide sign recognition was established. In the third, an example in Nanjing was used to verify the rationality and reliability of the evaluation model.

2.1. Participants. Sampling was necessary to a large population [11], so, in the first stage, the questionnaires were distributed to drivers from different occupations, including university students, researchers, bus drivers, and driving coaches. The ages of all participants were mainly between 20 and 60 years, and there were three groups about the ages: 1825 years, $26-50$ years, and 50 or more. The number of males and females was quite fair.

\subsection{Survey Instrument}

\subsubsection{Survey on Influence Factors of Guide Sign}

(1) Selection of Influence Factors. The first step was to find out the main influence factors of guide sign recognition. On the basics of the literature and field survey, the main factors were summarized and divided into static elements and dynamic elements (Table 1). An entire survey was time-consuming and undesirable, so only 11 of the main influence factors were selected based on ergonomics and the screening of experts. The ergonomics is a cross discipline that regards human, machine, and environment as a whole; its task is to optimize the working conditions and obtain higher efficiency.

(2) Content of Questionnaire. The questionnaire included two parts. Part A was the drivers' personal characteristics with four closed-ended questions, including gender, age, occupation, and years of driving license (Table 2). In order
TABLE 1: Main influence factors of guide sign recognition.

\begin{tabular}{ll}
\hline Influence factors & Contents \\
\hline Static elements & $\begin{array}{l}\text { Shape, size, ground color, setting } \\
\text { position, sign height, color contrast, sign } \\
\text { number, and road complexity }\end{array}$ \\
\hline & $\begin{array}{l}\text { Static and kinetic eyesight, response time, } \\
\text { speed, illumination, reflection, indistinct } \\
\text { degree, occlusion degree, character } \\
\text { number, size and complexity, weather, } \\
\text { traffic condition, vehicles and machinery, } \\
\text { and motor ability of driver }\end{array}$ \\
\hline
\end{tabular}

to maintain comfort in providing answers, participants were not required to put their names or telephone numbers on the questionnaires.

Part B was 18 questions to evaluate the degree of importance between each two factors. They were illustrated in color along with 9 choices (shown in Table 2). The questionnaire was designed based on the theory of analytic hierarchy process (AHP); 9 kinds of proportion were used to describe the relative importance.

(3) Questionnaire Survey. Two forms were adopted to make the survey. Online survey seemed to be much more convenient, while field survey could ensure the diversity of participants. To gain trust and get sincere response, participants were clearly reminded that this survey was not an exam, personal information was not taken, and no legal action would be applied. During the surveys, nearly each participant was equipped with one interviewer to avoid copying, cheating, and answering as a group, and there was less misunderstanding about the content of questionnaire in this way. When a participant preferred to answer verbally, interviewers simply wrote his/her answer on the questionnaire without interfering. The process which started in Nanjing in April, 2014, took over 10 days to finish.

\subsubsection{Evaluation Model of Guide Sign Recognition}

(1) Hierarchical Structure of Evaluation Index. According to the advice of experts and taking full consideration of psychophysical and physiological nature of a human, 11 influence factors were selected and divided into three categories. The evaluation model included three layers: target layer, rule layer, and index layer (Figure 1).

(2) Determination of Index Scores. Scores of index layer $\left(F_{i j}\right)$ were obtained by a questionnaire survey. A five-score system was used in order to facilitate the comparison and determination of index score (Table 3). The criterion of grading was based on the latest National Standards of the People's Republic of China for Part 2 of Road Sign and Marking (GB5768-2009) issued in April 2009. There were two assumptions in this research: the design speed is between 40 and $70 \mathrm{~km} / \mathrm{h}$ and the driver's vision is 0.8 . 
TABLE 2: Questionnaire sections: (a) drivers' characteristics and (b) sample of questions.

(a)

\begin{tabular}{lll}
\hline Gender & $\square$ Male & $\square$ Female \\
Age & $\square 18-25$ & $\square$ Over 50 \\
Education level & $\square$ Below university & $\square$ 26-50 \\
Years of license & $\square$ Less than 2 years & \\
\hline
\end{tabular}

(b)

\begin{tabular}{lcc}
\hline & What is the relative importance when "character size" is compared to "character number"? & \\
$\square 1: 9$ & $\square 2: 8$ & $\square 3: 7$ \\
$\square 4: 6$ & $\square 5: 5$ & $\square 6: 4$ \\
$\square 3: 7$ & $\square 8: 2$ & $\square 9: 1$ \\
\hline
\end{tabular}

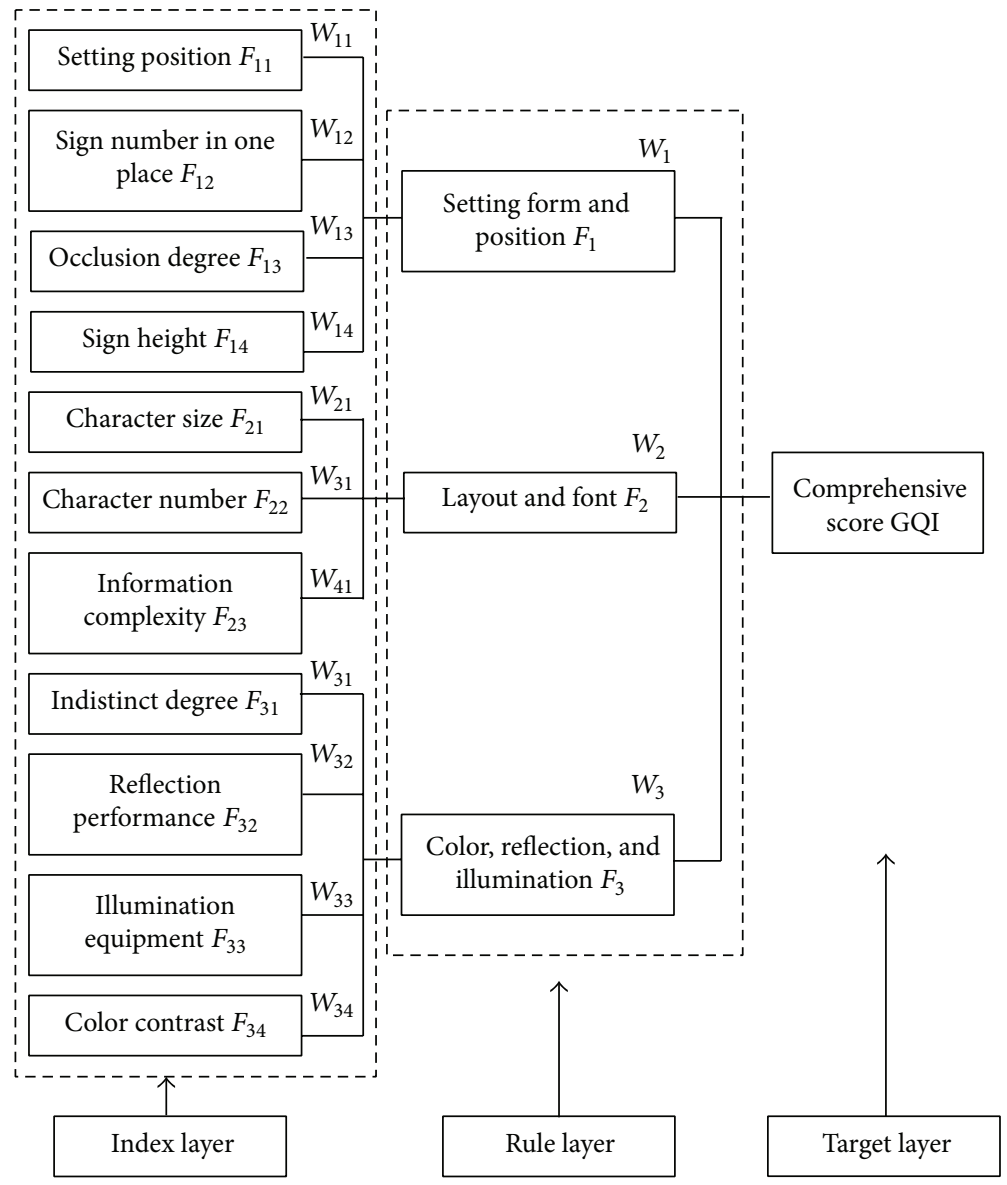

Figure 1: Hierarchical structure of evaluation index.

(3) Determination of Index Weights. Weights of index layer $\left(W_{i j}\right)$ and rule layer $\left(W_{i}\right)$ were obtained through AHP; the comprehensive weight directly reflected the importance of 11 influence factors that affected guide sign recognition. The comparison matrix was established based on the data of first stage. In order to assure a certain quality level of a decision, a consistency check on the comparison matrix was needed. The comparisons are assumed to be internally coherent when the consistency ratio $\mathrm{CR} \leq 0.1$; otherwise the comparisons must be repeated [12].
(4) Calculation of Comprehensive Score. The comprehensive score is given by the equations below:

$$
\begin{aligned}
F_{i} & =\sum W_{i j} F_{i j} \quad(i=1,2,3, j=1,2,3,4) \\
\mathrm{GQI} & =\sum_{i=1}^{3} W_{i} F_{i} .
\end{aligned}
$$




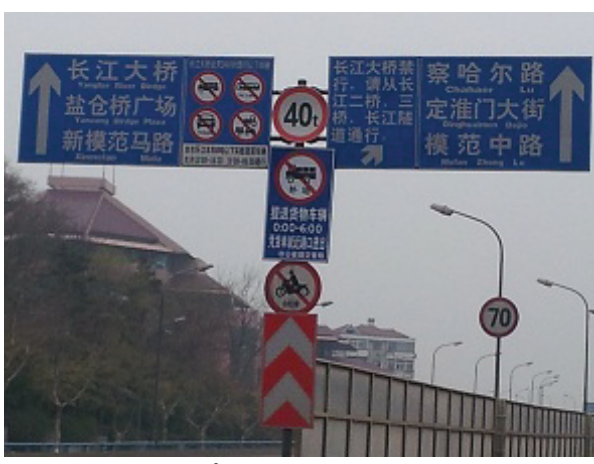

Before reconstruction

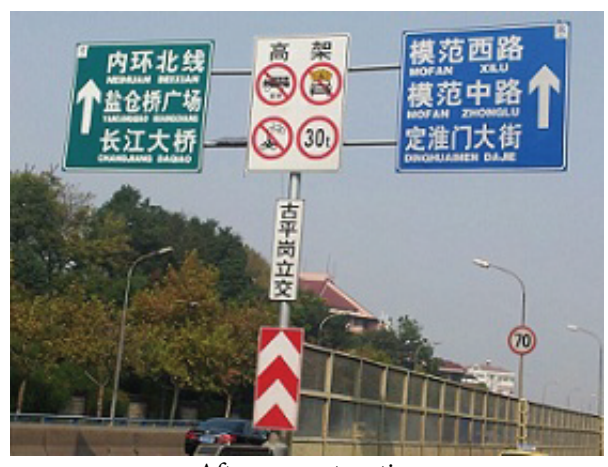

After reconstruction

FIgURE 2: Case of guide sign.

TABLE 3: Example of evaluation standard.

\begin{tabular}{|c|c|c|}
\hline \multicolumn{2}{|r|}{ Date } & \multirow{2}{*}{$\begin{array}{c}\text { Name } \\
\text { Interval Score }\end{array}$} \\
\hline Index & Standard & \\
\hline \multirow{4}{*}{ Character size } & $\begin{array}{l}\text { Character height is less than } \\
25 \mathrm{~cm}\end{array}$ & $<2.0$ \\
\hline & $\begin{array}{l}\text { Character height is between } 25 \\
\text { and } 40 \mathrm{~cm}\end{array}$ & $2.0 \sim 3.0$ \\
\hline & $\begin{array}{l}\text { Character height is between } 40 \\
\text { and } 50 \mathrm{~cm}\end{array}$ & $3.0 \sim 4.0$ \\
\hline & $\begin{array}{l}\text { Character height is more than } \\
50 \mathrm{~cm}\end{array}$ & $4.0 \sim 5.0$ \\
\hline \multirow{4}{*}{$\begin{array}{l}\text { Character } \\
\text { number }\end{array}$} & $\begin{array}{l}\text { Character number is more than } \\
20\end{array}$ & $<2.0$ \\
\hline & $\begin{array}{l}\text { Character number is between } 13 \\
\text { and } 20\end{array}$ & $2.0 \sim 3.0$ \\
\hline & $\begin{array}{l}\text { Character number is between } 7 \\
\text { and } 12\end{array}$ & $3.0 \sim 4.0$ \\
\hline & Character number is less than 7 & $4.0 \sim 5.0$ \\
\hline \multirow{4}{*}{$\begin{array}{l}\text { Information } \\
\text { complexity }\end{array}$} & $\begin{array}{l}\text { The number of destinations is } \\
\text { more than } 6\end{array}$ & $<2.0$ \\
\hline & $\begin{array}{l}\text { The number of destinations is } \\
\text { between } 5 \text { and } 6\end{array}$ & $2.0 \sim 3.0$ \\
\hline & $\begin{array}{l}\text { The number of destinations is } \\
\text { between } 3 \text { and } 4\end{array}$ & $3.0 \sim 4.0$ \\
\hline & $\begin{array}{l}\text { The number of destinations is } \\
\text { between } 1 \text { and } 2\end{array}$ & $4.0 \sim 5.0$ \\
\hline
\end{tabular}

\subsubsection{Case Study}

(1) Case Selection. In order to get a more intuitional result, two guide signs (see Figure 2) at the same location of Nanjing were selected to be research objects. The former was before reconstruction (March 2013) while the latter was after reconstruction (November 2014).

(2) Data Collection. In order to get scores of the two guide signs, ten researchers were invited to complete the questionnaire. Scores were all accurate to the first decimal place and the average score was adopted to calculate the comprehensive score.
TABLE 4: Cronbach's alpha for each scale.

\begin{tabular}{lcc}
\hline Scale & Cronbach's alpha & Reliability \\
\hline Rule layer & 0.790 & Good \\
Setting form and position & 0.648 & Acceptable \\
Layout and font & 0.704 & Good \\
Color, reflection, and illumination & 0.713 & Good \\
Overall layer & 0.806 & Good \\
\hline
\end{tabular}

TABLE 5: Results of KMO and Bartlett's Test.

\begin{tabular}{lcc}
\hline Scale & KMO & Probability \\
\hline Rule layer & 0.653 & 0 \\
Setting form and position & 0.686 & 0 \\
Layout and font & 0.691 & 0 \\
Color, reflection, and illumination & 0.618 & 0 \\
Overall layer & 0.547 & 0 \\
\hline
\end{tabular}

\section{Results and Discussion}

3.1. Personal Information of Participants. The questionnaires were distributed to 550 drivers and 510 drivers responded; the response rate of $93 \%$ was achieved. The major results were that (a) $57 \%$ participants were male; (b) most participants $(72 \%)$ were in the age group of 26-50 years, $19 \%$ were in the age group of $18-25$ years, and $9 \%$ were in the age group of over 50 years; (c) $80 \%$ participants had the education level of university or above; (d) 74\% participants had more than 2-year licenses. The large proportion of highly educated participants promoted the accuracy of results according to the conclusion that drivers with higher levels of education background presented better comprehension [13].

\subsection{Statistical Analysis of Questionnaire}

(1) Internal Consistency Reliability. Cronbach's alpha is considered an adequate measure of internal consistency. Cronbach's alpha was calculated for each scale separately (shown in Table 4), and all statistical analysis was performed using the Statistical Package for the Social Science (SPSS). A low Cronbach's alpha indicates a lack of correlation between the items 
TABLE 6: Results of factor analysis.

(a) KMO and Bartlett's Test

\begin{tabular}{lc}
\hline Kaiser-Meyer-Olkin Measure of Sampling Adequacy & .653 \\
Bartlett’s Test of Sphericity & \\
Approx. Chi-Square & 57.931 \\
df & 3 \\
Sig. & .000 \\
\hline
\end{tabular}

(b) Communalities

\begin{tabular}{lcc}
\hline & Initial & Extraction \\
\hline VAR00001 & 1.000 & .841 \\
VAR00002 & 1.000 & .696 \\
VAR00003 & 1.000 & .676 \\
\hline
\end{tabular}

Extraction method: Principal Component Analysis.

(c) Total variance explained

\begin{tabular}{|c|c|c|c|c|c|c|}
\hline \multirow{2}{*}{ Component } & \multicolumn{3}{|c|}{ Initial eigenvalues } & \multicolumn{3}{|c|}{ Extraction sums of squared loadings } \\
\hline & Total & $\%$ of variance & Cumulative \% & Total & $\%$ of variance & Cumulative $\%$ \\
\hline 1 & 2.213 & 73.774 & 73.774 & 2.213 & 73.774 & 73.774 \\
\hline 2 & .531 & 17.713 & 91.486 & & & \\
\hline 3 & .255 & 8.514 & 100.000 & & & \\
\hline
\end{tabular}

Extraction method: Principal Component Analysis.

in a scale, which makes summarizing the items unjustified. Conventionally, values from 0.6 to 0.7 are acceptable, whereas values greater than 0.7 are good [14].

(2) Construct Validity. A factor analysis was made to verify the construct validity of questionnaire. The Kaiser-MeyerOlkin Measure of Sampling Adequacy (KMO) and Bartlett's Test of Sphericity were created to test if the dataset was suitable for factor analysis [15]. The results (Table 5) showed that it was practical to make factor analysis (KMO $>0.5$ and $P<$ 0.05). The factor analysis was done using Principle Components Analysis in the statistical program SPSS. Due to space limitations, only the result of rule layer was given and illustrated with the original output of SPSS 19.0 (shown in Table 6).

3.3. Weights of Influence Factors. Weights of rule layer reflected the significance of different categories, and weights of index layer described the relative importance of different factors in the same category, while the comprehensive weights presented an overall comparison. Weights were all accurate to the third decimal place (Table 7). Due to the tedious process of calculation, results of consistency check were not included here.

\subsection{Evaluation Model}

(1) Calculation of Comprehensive Score. Substituting weights of index layer and rule layer into (1) yielded

$$
\begin{aligned}
& F_{1}=0.338 F_{11}+0.185 F_{12}+0.313 F_{13}+0.164 F_{14}, \\
& F_{2}=0.367 F_{21}+0.306 F_{22}+0.327 F_{23},
\end{aligned}
$$

$$
\begin{aligned}
F_{3} & =0.339 F_{31}+0.244 F_{32}+0.226 F_{33}+0.191 F_{34}, \\
\mathrm{GQI} & =0.414 F_{1}+0.345 F_{2}+0.241 F_{3} .
\end{aligned}
$$

(2) Grading of Guide Sign Recognition. The comprehensive score was divided into five grades corresponding to different levels of recognition (Table 8 ).

\subsection{Case Evaluation}

(1) Scores of Index. The method adopted here combined with qualitative evaluation and quantitative calculation; the results (shown in Table 9) presented an objective comparison between the two guide signs.

(2) Level of Recognition. Based on model (2) and scores of evaluation index (see Table 9), the comprehensive scores of the two guide signs were obtained (Table 10). The result shows that the reconstruction project has improved its recognition to some degree. However, the level of recognition after reconstruction is " $\mathrm{B}$ " rather than " $\mathrm{A}$ "; it seems to not be so satisfactory as expected. The reasons may be as follows: (a) too many destinations increase the complexity of information; (b) different kinds of traffic signs may weaken drivers' recognition.

(3) Further Improvement. In order to give drivers plenty of time to understand information and take effective measures, they should be noticed in advance. Therefore, two ways may contribute to the improvement of guide sign recognition: 
TABLE 7: Weights of different influence factors.

\begin{tabular}{lccc}
\hline Weight of rule layer $\left(W_{i}\right)$ & Influence factor & Weight of index layer $\left(W_{i j}\right)$ & Comprehension weight \\
\hline \multirow{2}{*}{ Setting form and position $\left(W_{1}=0.414\right)$} & Setting position & 0.338 & 0.140 \\
& Sign number in one place & 0.185 & 0.077 \\
& Occlusion degree & 0.313 & 0.130 \\
& Sign height & 0.164 & 0.068 \\
\hline \multirow{2}{*}{ Layout and font $\left(W_{2}=0.345\right)$} & Character size & 0.367 & 0.127 \\
& Character number & 0.306 & 0.106 \\
& Information complexity & 0.327 & 0.113 \\
Color, reflection, and illumination $\left(W_{3}=0.241\right)$ & Indistinct degree & 0.339 & 0.082 \\
& Reflection performance & 0.244 & 0.059 \\
& Illumination equipment & 0.226 & 0.054 \\
& Color contrast & 0.191 & 0.046 \\
\hline
\end{tabular}

TABLE 8: Grading of guide sign recognition.

\begin{tabular}{lccc}
\hline Level & $\begin{array}{c}\text { Comprehensive } \\
\text { score }(G Q I)\end{array}$ & Color & Evaluation \\
\hline A & $4.0 \sim 5.0$ & Green & Very good \\
B & $3.0 \sim 4.0$ & Blue & Good \\
C & $2.0 \sim 3.0$ & Yellow & Ordinary \\
D & $1.0 \sim 2.0$ & Orange & Poor \\
E & $<1.0$ & Red & Very poor \\
\hline
\end{tabular}

TABLE 9: Scores of evaluation index.

\begin{tabular}{|c|c|c|}
\hline \multirow[b]{2}{*}{ Index } & \multicolumn{2}{|c|}{ Score } \\
\hline & $\begin{array}{c}\text { Before } \\
\text { reconstruction }\end{array}$ & $\begin{array}{c}\text { After } \\
\text { reconstruction }\end{array}$ \\
\hline Setting position & 2.6 & 2.6 \\
\hline Sign number in one place & 1.2 & 1.8 \\
\hline Occlusion degree & 4.8 & 4.9 \\
\hline Sign height & 4.2 & 4.5 \\
\hline Character size & 0.8 & 4.3 \\
\hline Character number & 0.6 & 1.8 \\
\hline Information complexity & 0.9 & 1.7 \\
\hline Indistinct degree & 4.4 & 4.8 \\
\hline Reflection performance & 4.2 & 4.5 \\
\hline Illumination equipment & 3.9 & 4.2 \\
\hline Color contrast & 4.1 & 4.4 \\
\hline
\end{tabular}

TABLE 10: Level of recognition.

\begin{tabular}{lccc}
\hline Guide sign & Comprehensive score & Level & Evaluation \\
\hline Before reconstruction & 2.6 & $\mathrm{C}$ & Ordinary \\
After reconstruction & 3.5 & $\mathrm{~B}$ & Good \\
\hline
\end{tabular}

(a) a sign in advance would be effective according to the conclusion that early warnings should be used for reduced recognition [16]; (b) the regulatory sign should be moved to the entrance of the road so that drivers can take measures earlier and avoid wasting time.
3.6. Limitations. Despite the success of revealing importance of different influence factors and establishing an evaluation model of guide sign recognition, there were several limitations to the experimental design used in this study. First, the sample size of questionnaire survey is not enough due to the large number of drivers in Nanjing. However, at least, it shed some light on the topic. Second, there are many factors that can affect guide sign recognition and only 11 factors were selected to survey. Third, the improvement of guide sign has not been studied in detail; it would be the focus of future research. Fourth, warning signs and regulatory signs are as important as guide sign; they should be considered in later study.

\section{Conclusion}

The experiment was successful in studying the specific effects of different influence factors and the evaluation model of guide sign recognition with a convenience sample of drivers in Nanjing. There were some limitations in the study and some of the very basic questions need further research. Nevertheless, the findings provided the following useful information for helping researchers understand how factors affect guide sign recognition and propose effective measures.

(1) Among the 11 factors surveyed in this study, the setting position, occlusion degree, and character size of guide sign had the most significant influence on its recognition, and weights of them were $0.140,0.130$, and 0.127 , respectively.

(2) The evaluation model of guide sign recognition was based on AHP method and questionnaire survey; the comprehensive score was given by (2). In consideration of the traffic environment, cost, and some other factors, the level of "B" or above would be acceptable.

(3) The recognition level of the case in this study was raised from "C" to " $\mathrm{B}$ "; namely, its recognition was distinctly improved because of the reconstruction project. 


\section{Conflict of Interests}

All authors declare that there is no conflict of interests regarding the publication of this paper.

\section{Acknowledgments}

This research was supported in part by the National Natural Science Foundation of China with Grants nos. 51308192 and 51208261 and by the Science Foundation of Ministry of Education of China with Grant no. 12YJCZH062. The authors would like to show great appreciation for this support.

\section{References}

[1] C. Y. Fang, C. S. Fuh, P. S. Yen, S. Cherng, and S. W. Chen, "An automatic road sign recognition system based on a computational model of human recognition processing," Computer Vision and Image Understanding, vol. 96, no. 2, pp. 237-268, 2004.

[2] M. Li, M. Huang, Z. M. Niu, and M. L. Rao, "Deployment model for urban guide signs based on road network topology," Procedia-Social and Behavioral Sciences, vol. 96, pp. 1631-1639, 2013.

[3] US Department of Transportation, Annual Report on Highway Safety Improvement Programs, US Department of Transportation, 1989.

[4] A. W. Y. Ng and A. H. S. Chan, "The effects of driver factors and sign design features on the comprehensibility of traffic signs," Journal of Safety Research, vol. 39, no. 3, pp. 321-328, 2008.

[5] X. W. Gao, L. Podladchikova, D. Shaposhnikov, K. Hong, and N. Shevtsova, "Recognition of traffic signs based on their colour and shape features extracted using human vision models," Journal of Visual Communication and Image Representation, vol. 17, no. 4, pp. 675-685, 2006.

[6] H. Al-Madani and A.-R. Al-Janahi, "Assessment of drivers' comprehension of traffic signs based on their traffic, personal and social characteristics," Transportation Research Part F: Traffic Psychology and Behaviour, vol. 5, no. 1, pp. 63-76, 2002.

[7] M. S. Prieto and A. R. Allen, "Using self-organising maps in the detection and recognition of road signs," Image and Vision Computing, vol. 27, no. 6, pp. 673-683, 2009.

[8] X. Liu and J. Lu, "The technology of road guide signs setting in large interchanges," Procedia-Social and Behavioral Sciences, vol. 96, pp. 538-547, 2013.

[9] F. Zaklouta and B. Stanciulescu, "Real-time traffic sign recognition in three stages," Robotics and Autonomous Systems, vol. 62, no. 1, pp. 16-24, 2014.

[10] C. Souani, H. Faiedh, and K. Besbes, "Efficient algorithm for automatic road sign recognition and its hardware implementation," Journal of Real-Time Image Processing, vol. 9, no. 1, pp. 79-93, 2014.

[11] J. E. Bartlett and J. W. Kotrlik, "Organizational research: determining appropriate sample size in survey research," Information Technology, Learning, and Performance Journal, vol. 19, no. 1, pp. 43-44, 2001.

[12] D. Podgórski, "Measuring operational performance of OSH management system - a demonstration of AHP-based selection of leading key performance indicators," Safety Science, vol. 73, pp. 146-166, 2015.
[13] H. Al-Madani and A. R. Al-Janahi, "Role of drivers' personal characteristics in understanding traffic sign symbols," Accident Analysis \& Prevention, vol. 34, no. 2, pp. 185-196, 2002.

[14] G. Haugan and J. Drageset, "The hospital anxiety and depression scale-dimensionality, reliability and construct validity among cognitively intact nursing home patients," Journal of Affective Disorders, vol. 165, pp. 8-15, 2014.

[15] A. Hedlund, M. Åteg, I.-M. Andersson, and G. Rosén, "Assessing motivation for work environment improvements: internal consistency, reliability and factorial structure," Journal of Safety Research, vol. 41, no. 2, pp. 145-151, 2010.

[16] A. Borowsky, D. Shinar, and Y. Parmet, "Sign location, sign recognition, and driver expectancies," Transportation Research Part F: Traffic Psychology and Behaviour, vol. 11, no. 6, pp. 459465, 2008. 


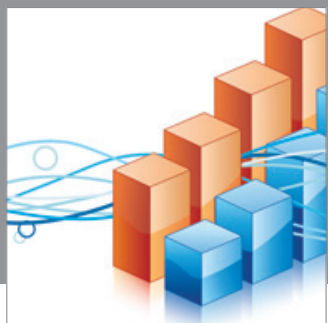

Advances in

Operations Research

mansans

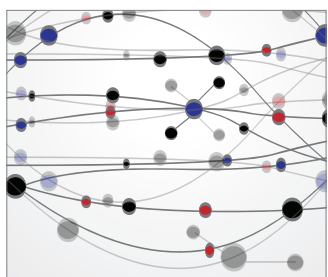

The Scientific World Journal
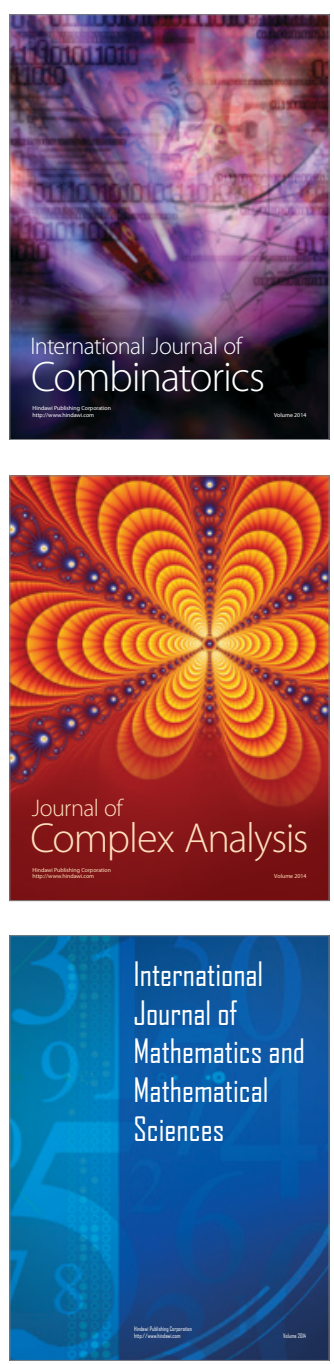
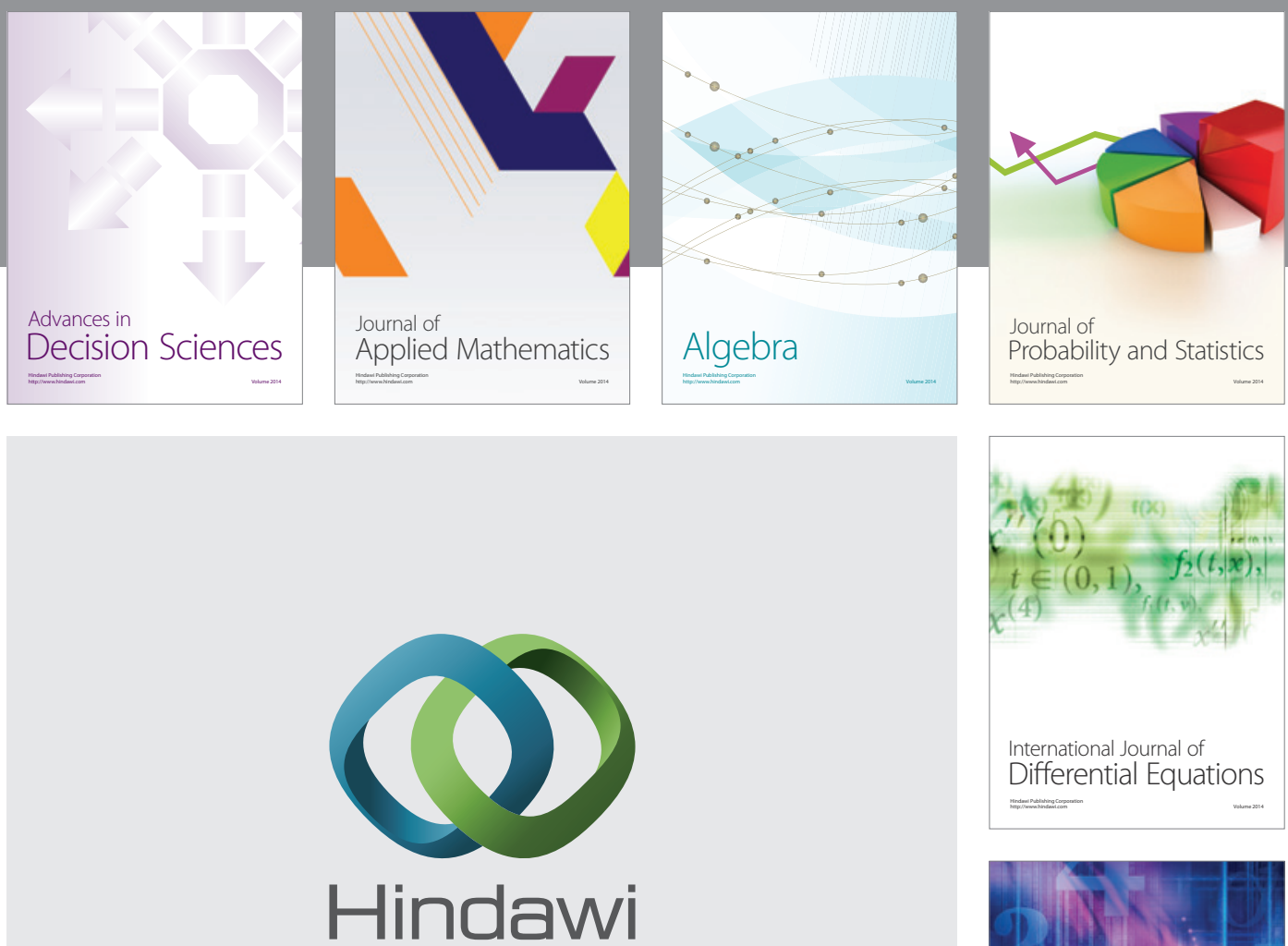

Submit your manuscripts at http://www.hindawi.com
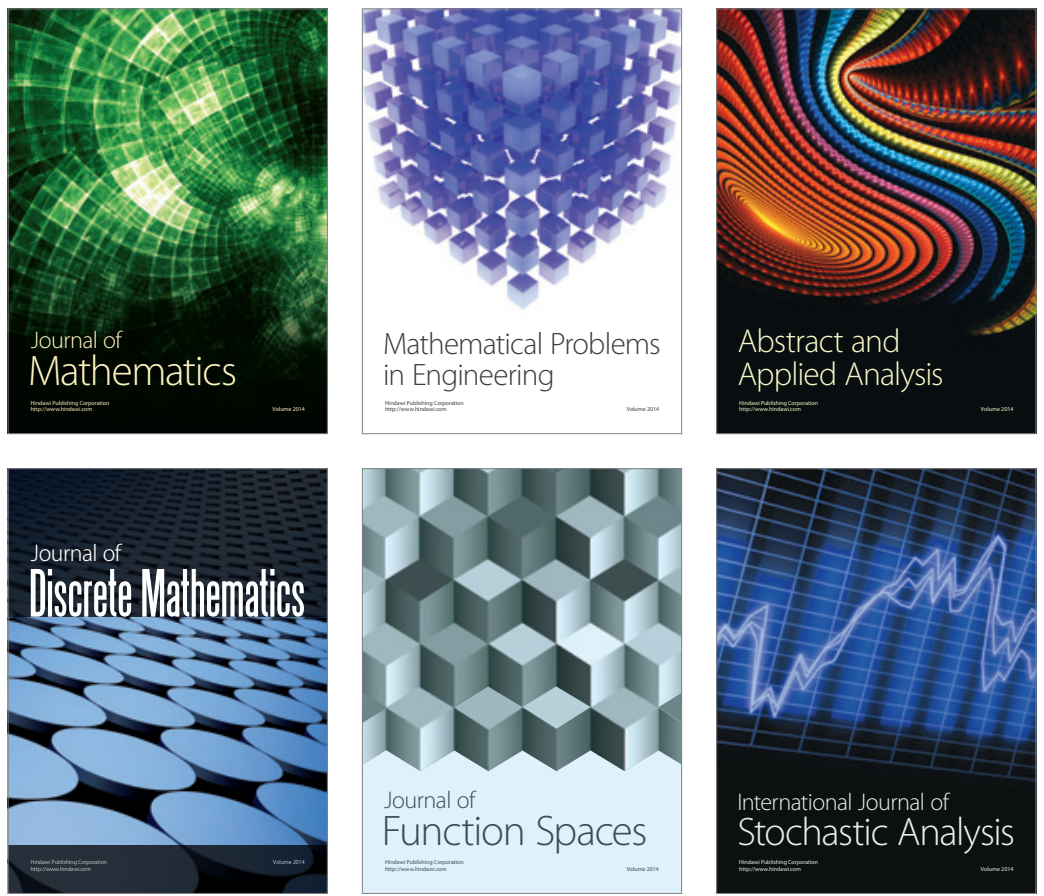

Journal of

Function Spaces

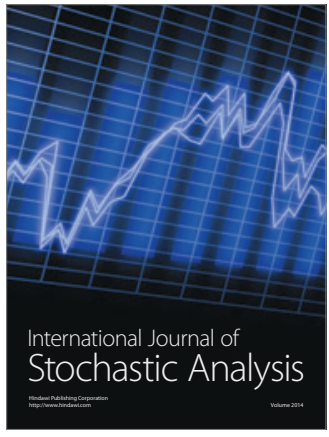

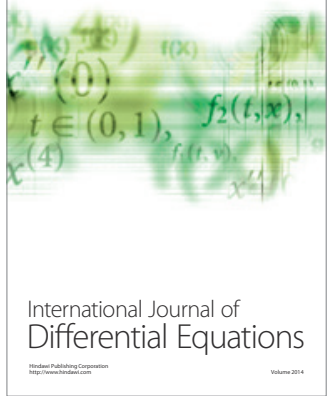
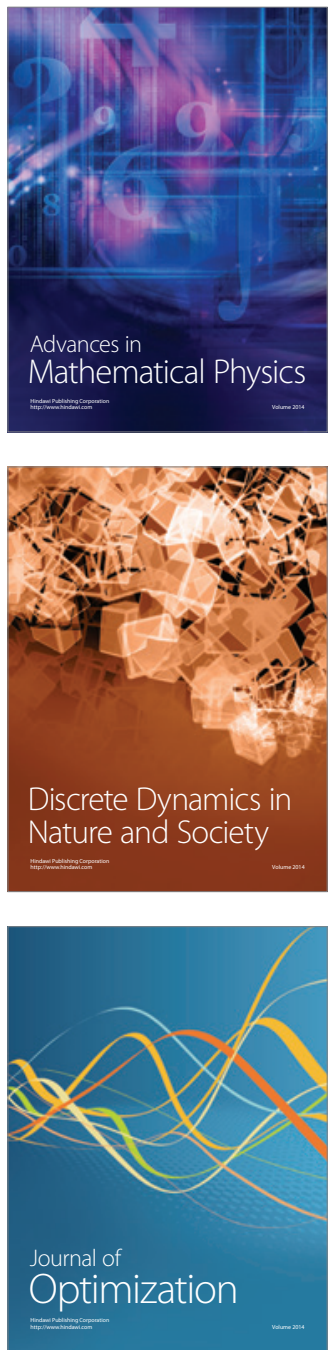